\title{
KOLAJEN EKSTRAKSİYON YÖNTEMLERİNİN KARŞILAŞTIRILMASI
}

\author{
Özge Ata*, Şebnem Tavman
}

Ege Üniversitesi, Mühendislik Fakültesi, Gıda Mühendisliği Bölümü, İzmir, Türkiye

Geliş / Received: 08.11.2018; Kabul / Accepted: 03.03.2019; Online bask1 / Published online: 03.04.2019

Ata, Ö., Tavman, Ş. (2019). Kolajen ekstraksiyon yöntemlerinin karşılaştırılması. GIDA (2019) 44 (3): 383-395 doi: 10.15237/gida.GD18112

Ata, Ö., Tavman, S.. (2019). Comparison of collagen extraction methods. GIDA (2019) 44 (3): 383-395 doi: 10.15237/gida.GD18112

\section{ÖZ}

Kolajen, memelilerde en bol bulunan proteindir. Gıda, ilaç, kozmetik ve deri endüstrisinde yaygın olarak kullanılan kolajen, ticari olarak, domuz ve sığır gibi memelilerin yan ürünlerinden elde edilmektedir. Şimdiye kadar tespit edilen en az 20 farklı kolajen tipi vardır. Vücuttaki kolajenlerin çoğu tip 1, tip 2 ve tip 3 grubuna aittir. Kolajen özellikleri, uygulanan ön işlem ve ekstraksiyon yöntemine göre değişmektedir. Tuzla çöktürme, asitle hidroliz ve enzimatik hidroliz yöntemleri kolajen ekstraksiyonu için kullanılmaktadır. Bununla beraber, son yıllarda yapılan çalısmalar, ultrason kullanımının ekstraksiyon verimini artırmada etkili olduğunu göstermiştir. Bu derlemede, ön işlemlerin ve farklı ekstraksiyon yöntemlerinin kolajen verimine etkisi ile ilgili yapilan çalışmalar incelenmiştir.

Anahtar kelimeler: Kolajen, ekstraksiyon, ultrason

\section{COMPARISON OF COLLAGEN EXTRACTION METHODS}

\begin{abstract}
Collagen is the most abundant protein in mammals. Collagen, commonly used in the food, pharmaceutical, cosmetic and leather industries, is commercially derived from by-products of mammals, such as pig and bovine. There are at least 20 different types of collagen detected so far. Most of the collagen in the body belongs to type 1, type 2 and type 3. Collagen properties vary according to the pre-treatment and extraction method. Salting out, acid hydrolysis and enzymatic hydrolysis methods are used for collagen extraction. In addition, recent studies have shown that the use of ultrasound is effective in increasing the extraction efficiency. In this review, studies on the effect of pre-treatment and different extraction methods on collagen yield were investigated.
\end{abstract}

Keywords: Collagen, extraction, ultrasound

\footnotetext{
*Yazışmalardan sorumlu yazar / Corresponding author;

$\triangle$ ozgeata93@gmail.com, $\quad(0(+90) 2323882395$

且(+90) 2323427592
} 


\section{GİRIŞ}

Kolajen, deri, kemik, kıkırdak ve tendon gibi farklı bağ dokularda bulunan ve memelilerde toplam proteinin yaklaşı1k \%30'unu içeren lifli bir proteindir. Bağ dokuda son derece önemli yapısal bir protein olan kolajen molekülü, genellikle ağs1 veya lifsi yapidadir (Yang ve Shu, 2014). Ekstraselüler matriksin (ESM) önemli bir kısmını oluşturan kolajen biyolojik yapılardaki bağ rolü nedeniyle birçok canlı organizmada en çok bulunan moleküllerden biridir. Kolajen moleküllerinin ana görevi omurgalılara yapısal ve mekaniksel özellikler sağlamaktır (Ferraro vd., 2017).

Deri, kemik gibi kolajence zengin maddelerden sicak su ile ekstrakte edilen kolajen, jelatin olarak da bilinir. Jelatinin enzimatik veya asidik hidroliz yoluyla daha ileri derecede parçalanması sonucu ise suda çözünür formdaki kolajen hidrolizatı elde edilir. Kolajen hidrolizatının antioksidan, antiinflamatuar, antihipertansif, antiosteoporotik, antitümor gibi sağlığa faydalı birçok etkisi bulunur (Song ve Li, 2017). Kolajenin, çeşitli endüstriyel uygulamalara sahip olması kullanış1 biyomateryallerden biri olarak kabul görmesini sağlar (Lafarga ve Hayes, 2014). Yüksek protein içeriği ve su emme kapasitesi, jel oluşumu ve emülsiyonları oluşturma-stabilize etme gibi fonksiyonel özellikleri nedeniyle gida endüstrisinde kolajen ve jelatin için büyük bir talep vardır (Schmidt vd., 2016). Bununla beraber, geniş hammadde kaynaklarına sahip olması, yenilenebilir, parçalanabilir, biyo- uyumlu ve yapısının ayarlanabilir olması kolajen proteinin sahip olduğu avantajlardandır. Bu nedenle, sağlık ürünlerinde, gidalarda, kozmetikte, tıbbi malzemelerde yaygın şekilde kullanılır (Yang ve Shu, 2014).

Kolajen yapısına göre lifli, lifsiz (ağ oluşturucu,) fibril, mikrofibril (ipliksi) ve membran olarak sinıflandırılan en az 20 farklı kolajen tipi vardır. Her kolajen tipi ayırt edici amino asit sekansi ile moleküler yapisina sahiptir ve her biri dokuda benzersiz bir rol oynar (Cheng vd., 2009). Genellikle, kolajenlerdeki amino asit sekanslar1, enerji depolama kapasitesi, sertlik veya esneklikle ilgili fonksiyonel özelliklerden sorumludur
(Ehrlich vd., 2018). Kolajen yapisinda on dokuz farklı amino asit bulunur ve ortalama olarak kolajendeki toplam amino asitlerin \%57'sini glisin, prolin ve hidroksiprolin oluşturur ( $\mathrm{Li}$ ve $\mathrm{Wu}$, 2018).

Molar kütlenin, yapının, bileşimin dağılımı ve kolajenin fonksiyonel özellikleri, elde edildiği hammaddenin işlem koşullarına ve ekstraksiyon sürecinde kullanılan enzimin özgünlüğüne bağlıdır. Bu nedenle, yüksek verim ve en iyi kolajen özelliklerini elde etmek için her hammaddeye uygun ekstraksiyon sürecinin belirlenmesi gereklidir (Schmidt vd., 2016). Bu çalışmada, kolajen kaynakları, ön işlemlerin ve farklı ekstraksiyon proseslerinin kolajen verimine etkisi ile ilgili yapılan çalışmaların araştırılması amaçlanmıştır.

\section{KOLAJEN}

Kolajen, hayvanlarda bulunan farklı bağ dokuların temel yapısal proteinidir. Çoğunlukla tendonlar ve ligamentler gibi lifli dokularda bulunan kolajen ayrıca kornea, kıkırdak, kemik, kan damarları, bağırsak ve omurlar aras1 disklerde de bol miktarda bulunur (Sibilla vd., 2015).

Kolajen molekülleri, sarmal yapıda üç polipeptit zincirden meydana gelir. Polipeptit alt birimler olan $\alpha$-zincirler, kolajen molekülünün üçlü sarmalını oluşturur. İki $\alpha$ zinciri, $\beta$-peptit zinciri olarak bilinen bir peptit zincir dimerine dönüşürken, üç $\alpha$ zinciri, $\gamma$-peptit zinciri (tropokolajen molekülü) olarak bilinen peptit zincir trimerine dönüşür (Yang ve Shu, 2014). Her bir peptit zinciri yaklaşı $100 \mathrm{kDa}$ 'lık molar kütle ile ortalama $300 \mathrm{~nm}$ uzunluğunda, $1.5 \mathrm{~nm}$ çapındadır ve karakteristik üçlü bir sarmalda birbiri etrafinda sarılmıs tam 1050 aminoasit kalıntısı içerir (Lodish vd., 2000). Genel olarak, kolajendeki aminoasit dizisi tekrarlayan tripeptit birimidir (Gly-X-Y). Gly, glisin, X sıklikla prolin, $\mathrm{Y}$ ise hidroksiprolindir. Insanlarda bulunan ve literatürde rapor edilen en az yirmi farklı kolajen tipi vardır (Gelse vd., 2003; Ricard-Blum, 2011; Mohammadi vd., 2016; Ferraro vd., 2017; AvilaRodríguez vd., 2018; Bhagwat vd., 2018; Ehrlich vd., 2018). Ancak vücuttaki kolajenlerin \%80-90’1 tip 1, tip 2 ve tip 3 grubuna aittir. Diğer kolajen 
tipleri çok düşük miktarlarda, özellikle kalp kası, bağırsak mukozası, bazal membran ve akciğer gibi spesifik organlarda bulunur (Schmidt vd., 2016). Başlıca kolajen tipleri aşağıda özetlenmiştir:

Tip I kolajen $[\alpha 1(\mathrm{I})]_{2} \alpha 2(\mathrm{I})$ insan vücudunda en çok bulunan ve en dayanıklı olan kolajen tipidir. İki eşdeğer $\alpha 1$ ve bir $\alpha 2$ zincirinden oluşur. Başlıca deride, tendonlarda, kemikte, ligamentlerde ve bağ dokusunda bulunur (Krishnamoorthivd., 2017).

Tip II kolajen $[\alpha 1(\mathrm{II})]_{3}$, k1kırdak dokusunun başlica kolajenidir. Üç $\propto 1$ (II) zincirinden oluşur. Kıkırdaktaki toplam protein içeriğinin \%90-95'ini oluşturur (Jeevithan vd., 2015). Etki mekanizmas1 itibariyle, osteoartrit/romatoid artrit gibi eklem hastalıklarının tedavisinde kullanılır.
Tip III kolajen $[\alpha 1(\mathrm{III})]_{3}$ ağ yapilı liflerden oluşmaktadır ve ekstraselüler matrisin temel bileşenidir. Üç $\alpha 1$ (III) zincirinden oluşur. Genellikle tip I kolajenle beraber bulunur. Cildin elastikiyetini ve sıkılığını sağlar. Kan damarında, yaralarda ve belirli tümörlerde bulunur (Liu vd., 2001).

Kolajen, yapisı ve üç boyutlu organizasyonu temel alındığında, fibril oluşturan kolajenler, ăg oluşturucu kolajenler, kesintili üçlü sarmallı fibril ilişkili kolajenler (FACIT), ankraj fibrilleri, transmembran, bazal membran, mikrofibriler kolajen ve multipleksin olarak gruplandirllir. Çizelge 1'de farklı kolajen yapılarına ait kolajen tipleri ve dokudaki dağılımları listelenmiştir.

Çizelge 1. Farklı yapıdaki kolajen tipleri (Gelse vd., 2003)

\begin{tabular}{|c|c|c|}
\hline Familya & Tip & Bulunduğu yer \\
\hline \multirow[t]{5}{*}{ Fibril oluşturan kolajenler } & $\mathrm{I}$ & tendon, ligamentler, kemik, dermis \\
\hline & II & k1kırdak, cams1 cisim \\
\hline & III & deri, retiküler lif \\
\hline & $\mathrm{V}$ & akciğer, plasenta, kornea \\
\hline & $\mathrm{XI}$ & cams1 cisim, eklem k1kırdağ1 \\
\hline \multirow[t]{2}{*}{ A ̆g oluşturucu kolajenler } & VIII & endotel hücreleri \\
\hline & $\mathrm{X}$ & hipertrofik k1kırdak \\
\hline \multirow[t]{6}{*}{ FACIT kolajenler } & IX & k1kırdak, kornea, cams1 cisim \\
\hline & XII & perikondrium, ligamentler, tendon \\
\hline & XIV & dermis, tendon, plasenta, akciğer \\
\hline & XIX & rabdomiyosarkom hücresi \\
\hline & $\mathrm{XX}$ & embriyonik deri, sternal kıkırdak, tendon \\
\hline & XXI & kan damarı duvar1 \\
\hline Ankraj fibrilleri & VII & oral mukoza,deri \\
\hline \multirow[t]{2}{*}{ Transmembran kolajenler } & XIII & epidermis, saç folikülü, endomisyum \\
\hline & XVII & dermal - epidermal eklemler \\
\hline Bazal membran kolajenler & IV & bazal membran \\
\hline Mikrofibriler kolajen & VI & deri, kıkırdak, plasenta, omurlar arası disk \\
\hline \multirow[t]{3}{*}{ Multipleksin } & XV & fibroblastlar, düz kas hücreleri, böbrek \\
\hline & XVI & fibroblastlar, amniyon, keratinositler \\
\hline & XVIII & karaciğer, akciğer \\
\hline
\end{tabular}


Toplam kolajenin yaklaşık $\% 90$ 'ını oluşturan en bol ve yaygın kolajen familyası, fibril oluşturan kolajenlerdir (Gelse vd., 2003). Kolajen fibrilleri, dokuya bağlı olarak yaklaşık 12-500 $\mathrm{nm}$ aralığında değişmektedir (Kadler vd., 2007). Kolajen fibrilleri, kolajenlerin ve kolajen olmayan proteinlerin veya proteoglikanların makromoleküler alaşımları olarak düşünülebilir (Ricard-Blum vd., 2011). FACIT yapidaki kolajenler, nispeten kısa kolajenlerdir. Üçlü sarmal alanda kesintiye uğrarlar ve kolajen fibrillerinin yüzeylerinde bulunabilirler (Kadler vd., 2007). A $\breve{g}$ oluşturucu kolajen yapısındaki tip X ve VIII kolajenler yapisal olarak kısa zincirli kolajenlerdir. $\mathrm{Bu}$ kolajen tipleri altıgen ağlar oluşturur. Kolajen ağları, hücre ve dokuları destekleyici yapılar olarak işlev görür. Bununla beraber, gelişmekte olan embriyoları içerir ve korur; komşu hücreler için ankraj işlevi görür (Balasubramanian vd., 2012). Ankraj fibriller büyük ölçüde tip VII kolajenden oluşur. Tip VII kolajen, ESM fonksiyonu ve stabilitesi için çok önemlidir (Karsdal ve Mortensen, 2016). Membran kolajenleri, bazal membran ve transmembran olmak üzere 2 farklı formda bulunur. Hücre etkileşiminde önemli rol oynayan Tip IV kolajen, bazal membranin ana bileşenidir. Transmembran kolajen tipleri ise genellikle deride ve deri altı bağ yerlerinde bulunur. ESM'de geniş lifleri bir araya getiren mikrofibriler yapıdaki tip VI kolajen derinin önemli bir kolajen bileşenidir. Kolajen proteini, özel bir amino asit bileşimine sahip olmasıyla diğer proteinlerden farklıdır. Yapısında on dokuz farklı amino asit bulunduran kolajen, zorunlu amino asitlerden histidin, izolösin, lösin, lizin, metiyonin, fenilalanin, treonin, tirozin ve valini içerir. Kolajenin amino asit karakteristiği olan hidroksiprolin, kolajenin termal stabilitesini belirler ve kolajenin kantitatif tayininde kullanilır (Włodarczyk vd., 2017). Bununla birlikte, hidroksiprolinin, hayvanların çoklu dokularında glisin sentezi, bağ doku yapısının onarımı, hücresel redoks reaksiyonlarının düzenlenmesi gibi birçok fonksiyonu vardır (Li ve Wu, 2018).

\section{KOLAJEN EKSTRAKSIYYONU Kolajen Kaynakları}

Kolajen ekstraksiyonu için en sık kullanılan hammaddeler, deri veya postlar, kemikler, tendonlar ve kıkırdaklardır (Gómez-Guillén vd., 2011). Ticari kolajenlerin birçoğu, özellikle sığır ve domuz gibi memeli hayvanların yan ürünlerinden elde edilir (Arumugam vd., 2018). Ancak, sığırlarda görülen deli dana hastalığı (BSE), ayakağız hastalığı (FMD) ve inanca dayalı kısitlamalar gibi problemler, araştırmacıları kolajen için farklı hammaddeler arayışına yönlendirmiştir. Bu gibi nedenlerle, son yıllarda yapılan çalışmalarda, balık yan ürünleri kolajen eldesi için alternatif ve güvenli bir kaynak olarak görülmektedir. Özellikle deri, pul ve yüzgeç gibi kolajence zengin olan yan ürünlere ilgi artmaktadır (Dun vd., 2008). Bununla beraber, kümes hayvanı kesim atıklarından kolajen ekstraksiyonuyla ilgili çalışmalar da literatürde mevcuttur. Çizelge 2'de kolajen ekstraksiyonunda kullanılan bazı hammaddeler görülmektedir.

Çizelge 2. Kolajen ekstraksiyonu ile ilgili çalışmalarda kullanılan materyal

\begin{tabular}{|c|c|c|}
\hline & Kullanılan Materyal & \\
\hline Memeli hayvanlar & Kümes havvanlar1 & Balık \\
\hline $\begin{array}{l}\text { Sığır derisi (De Moraes ve Cunha, } \\
\text { 2013) } \\
\text { Sığır kemiği (Ferraro vd., 2017) } \\
\text { Sığır tendonu (Ran ve Wang, } \\
\text { 2014) } \\
\text { Domuz testisi (Simões vd., 2014) } \\
\text { Domuz derisi (Yang ve Shu, 2014) } \\
\text { Koyun kemikleri (Gao vd., 2017) }\end{array}$ & $\begin{array}{l}\text { Tavuk ayağı (Liu vd., 2001; } \\
\text { Cheng vd., 2009; Hashim } \\
\text { vd., 2014; Zhou vd., 2016; } \\
\text { Dhakal vd., 2018) } \\
\text { Tavuk kemiği (Dong vd., } \\
\text { 2014) } \\
\text { Tavuk derisi (Lin vd., 2013; } \\
\text { Oechsle vd., 2016) }\end{array}$ & $\begin{array}{l}\text { Deri (Ninan vd., 2014; Sionkowska vd., } \\
\text { 2015; Sun vd., 2017; Ali vd., 2018; } \\
\text { Arumugam vd., 2018; Li vd., 2018) } \\
\text { Hava kesesi (Kaewdang vd., 2014) } \\
\text { Pul (Chuaychan vd., 2015; Chen vd., } \\
\text { 2016; Mahboob, 2015; Bhagwat ve } \\
\text { Dandge, 2016; Huang vd., 2016) } \\
\text { Balık Kılçı̆̆1 (Liu ve Huang, 2016; } \\
\text { Tsutaya vd., 2018) } \\
\text { Kıkırdak (Liang vd.,2014; Jeevithan } \\
\text { vd., 2015; Bu vd., 2017) } \\
\text { İskelet (Jeevithan vd., 2014) }\end{array}$ \\
\hline
\end{tabular}


Kolajen ekstraksiyonunda kullanilan hammaddelerin genelde deri, kemik, ayak ve pul gibi insan tüketimi amaciyla kullanılmayan hayvansal yan ürünlerden oluştuğu gözlenmiştir. Bu yan ürünlerin kullanılarak katma değeri yüksek olan kolajen üretilmesi, hayvansal atıkların da verimli bir şekilde değerlendirilmesine olanak sağlamaktadır.

\section{Ön İşlemler}

Kolajen ekstraksiyonu için hammaddeye göre farklılık gösteren bir asit veya alkali çözelti kullanılarak birtakım ön işlemler gerçekleştirilir. Ön işlemler, kolajen olmayan maddeleri uzaklaştırmak ve yüksek verime ulaşmak amacıyla uygulanır. Alkali işlemi, genel olarak kemik ve deri gibi kararlı ve son derece çapraz bağlanmış malzemeler için kullanılır (See vd., 2015). Alkali işlemde hammadde, sodyum hidroksit $(\mathrm{NaOH})$, magnezyum oksit $(\mathrm{MgO})$ ve kalsiyum hidroksit $\left(\mathrm{Ca}(\mathrm{OH})_{2}\right)$ gibi bazik bir çözelti ile muamele edilir. Özellikle $\mathrm{NaOH}$ muamelesi deride önemli bir şişmeye sebep olarak doku matriksindeki kütle transfer hızını arttırır ve kolajen ekstraksiyonunu kolaylaştırır (Liu vd., 2015a). Alkali işlemin ardından asit ile nötralizasyon işlemi, kolajen olmayan proteinleri uzaklaştırmakla birlikte iyi bir jel özelliği ve yüksek verimle sonuçlanabilecek nötr ya da zayıf asit ekstraksiyon ortamı da sağlar (Zhou ve Regenstein, 2005). Kullanilan asidin türü ve konsantrasyonu, şişme özelliklerine ve kolajenin çözünmesine büyük ölçüde etki eder (Manjula vd., 2015). Bununla birlikte, yüksek yağ içeriğine sahip deriler için, lifler yağ uzaklaştırma işlemiyle yumuşatılarak kolajen saflığ1 ve ekstraksiyon verimi arttırlabilmektedir. Xu vd. (2017) tarafindan yapılan bir çalışmada, geliştirilmiş ön işlemlerin (yağ uzaklaştırma ve ağartma) güney yayın balığı (Silurus meridionalis Chen) derisinden ekstrakte edilen kolajenin saflığ1 ve verimi üzerine etkileri değerlendirilmiştir. Elektroforez, hidroksiprolin içeriği ve ekstraksiyon hızının değerlendirilmesi sonucu, $\% 0.5$ hidrojen peroksit $\left(\mathrm{H}_{2} \mathrm{O}_{2}\right)$ çözeltisinde $(\mathrm{pH}$ 10) ağartma işlemi gerçekleştirilmiş ve yağdan arındırılmış deriden ekstrakte edilen kolajenin diğer ağartma koşullarına kıyasla daha yüksek verim ve saflık gösterdiği gözlenmiştir.
Uygulanan ön işlemler ile kullanılan kimyasalların türü ve konsantrasyonu ekstraksiyonun fonksiyonel etkinliği için önemlidir. Kolajen özellikleri, ön işlemlere bağlı olarak değişmektedir. Bu sebeple, ürün verimi ve kalitesi açısından kullanılacak olan kimyasalların türü ve konsantrasyonu iyi belirlenmelidir.

\section{Ekstraksiyon Yöntemleri}

Kolajen özellikleri hammaddeye ve ekstraksiyon koşullarına bağlı olarak değişir. En çok kullanilan ekstraksiyon yöntemleri kolajenin nötr tuzlu çözeltiler, asit çözeltileri ve enzimlerin eklendiği asit çözeltilerindeki çözünürlügüne dayanır (Schmidt vd., 2016).

\section{Tuzla Çöktürme}

Genel olarak tuz ile çöktürme yöntemi, ekstraksiyon ve çöktürme olarak 2 aşamadan meydana gelir. Tuzun konsantrasyonunu kontrol etmek, bu yöntemdeki kilit noktadır. Bir protein çözeltisine düşük tuz konsantrasyonlarında nötral tuz ilave edildiğinde, tuz molekülleri proteinlerin çözünürlügünü arttıran moleküller arasındaki elektrostatik enerjiyi azaltarak protein moleküllerinin çözünürlügünü arttırır (tuzla çözündürme $=$ salting in). Yüksek tuz konsantrasyonlarında nötral tuz ilave edildiğinde ise, hidrofobik gruplar etrafindaki su molekülleri tuz molekülleri tarafindan uzaklaştırılır; bu durumda hidrofobik etki artar, çözünürlük azalır ve proteinler çöker (tuzla çöktürme $=$ salting out). Tuzla çöktürme yönteminde, öncelikle çözünürlük arttırilarak proteinler ekstrakte edilir, sonrasında ise çözünürlük azaltılarak proteinlerin çökmesi sağlanır (Duong-Ly ve Gabelli, 2014). Çöktürme işleminde genellikle, $\mathrm{NaCl}$ (sodyum klorür), Tris-HCI (Tris (hidroksimetil) aminometan hidroklorür), fosfat veya sitrat çözeltisi gibi nötr tuz çözeltileri kullanılır (Yang ve Shu, 2014).

Kolajen ekstraksiyonunda tuzla çöktürme yönteminin prensibi esas olarak çözünür kolajeni dokulardan ekstrakte etmektir. Zhou vd. (2016) çalışmasında, tavuk ayaklarından tuzda (sodyum klorür), asitte (asetik asit) ve enzimde (pepsin) çözünür kolajen ekstraksiyonu gerçekleştirmiştir. Ön işlemleri tamamlanmış tavuk ayakları, tuzla 
ekstraksiyon işleminde $(0.05 \mathrm{~mol} / \mathrm{L}$ Tris- $\mathrm{HCl}$ içinde $0.45 \mathrm{~mol} / \mathrm{L} \mathrm{NaCl}, \mathrm{pH} 7.5)$ tuz çözeltisi içinde; asitle ekstraksiyon işleminde $0.5 \mathrm{~mol} / \mathrm{L}$ asetik asit çözeltisinde; enzimle ekstraksiyon işleminde $\% 0.1(\mathrm{w} / \mathrm{v})$ pepsin içeren $0.5 \mathrm{~mol} / \mathrm{L}$ asetik asit çözeltisinde 48 saat bekletilmiştir. Ekstraksiyon işlemi sonunda elde edilen her bir kolajenin verimi kıyaslandığında; tuzda çözünür kolajenin en düşük verime (\%1.13 kuru ağırlık bazında) sahip olduğu gözlenmiştir.

Duan vd. (2013) NaCl'nin kolajen çözeltisinin reolojik özelliklerini de etkilediğini bildirmiştir. Düşük NaCI konsantrasyonlanında $(0-0.1 \mathrm{~mol} / \mathrm{L})$ salting in etkisi ve çözeltilerin psödoplastik davranışının zayıfladığı tiksotropinin ise güçlendiği görülürken; yüksek $\mathrm{NaCI}$ konsantrasyonlarında (0.1-0.3 mol/L) salting out etkisi ve çözeltilerin psödoplastik davranışının güçlendiği ancak tiksotropide belirgin bir değişim olmadığ1 gözlenmiştir. Hayvan dokularında, protein moleküllerinin birbirine çapraz bağlı olmasından dolayı çözünür kolajen miktarı da azdır, bu durum genellikle düşük kolajen verimi ve saflığına yol açar (Liu vd., 2015b). Bu yüzden tuzla ekstraksiyon yönteminin kullanımı sınırlıdır.

\section{Asitle Hidroliz}

Asit hidrolizi, asetik asit, sitrik asit ve laktik asit gibi organik asitler ve hidroklorik asit gibi inorganik asitler kullanılarak gerçekleştirilir. Organik asitler çapraz bağlanmamış kolajenleri çözme yeteneğine sahiptir. Aynı zamanda kolajen içindeki zincirler arası çapraz bağların bir kısmını kırarak ekstraksiyon sirasinda kolajenin daha fazla çözünmesini sağlar (Liu vd., 2015a). Asetik asit, kolajen ekstraksiyonu için en yaygin kullanılan organik çözgendir. Chen vd. (2016) tarafindan yapılan çalışmada tatlısu çipurasının (Oreochromis niloticus) pul ve derisinden asit-çözünür kolajen ekstraksiyonu gerçekleştirilmiştir. Ön işlemleri tamamlanmış pul ve deriler, $0.5 \mathrm{~mol} / \mathrm{L}$ asetik asit ile $4^{\circ} \mathrm{C}$ 'de 24 saat boyunca muamele edilmiştir. Deri ve pullardan ekstrakte edilen asit-çözünür kolajen (ASC) verimi sirasiyla 27.2g / $100 \mathrm{~g}$ ve $3.2 \mathrm{~g}$ $/ 100 \mathrm{~g}$ (kuru ağırlık) olarak belirlenmiştir. Wang vd. (2008), asetik asit konsantrasyonun (0.3, 0.5 ve $0.8 \mathrm{~mol} / \mathrm{L})$, sicaklı̆ın $\left(10,20\right.$ ve $\left.30^{\circ} \mathrm{C}\right)$ ve ekstraksiyon süresinin $(12,24$ ve 36 saat) ekstraksiyon verimine etkisini değerlendirerek, ot sazan1 (Ctenopharyngodon idella) derisinden ASC ekstraksiyon koşullarını optimize etmiştir. Test edilen üç değişkenin de kolajen ekstraksiyonunu belirgin şekilde etkilediği gözlenmiştir. Sicaklığın ve asetik asit konsantrasyonunun artışıla verim belirli bir değere kadar artış göstermiş, daha sonra ise azalmıştır. Ot sazanı derisinden en yüksek verimle ASC elde etmek için optimum koşullar; asetik asit konsantrasyonu $0.54 \mathrm{~mol} / \mathrm{L}$, sicaklik $24.7^{\circ} \mathrm{C}$ ve süre 32.1 saat olarak belirlenmiştir. Liu vd. (2001) tarafindan yapılan çalışmada, tavuk ayaklarından kolajen ekstraksiyonu için farklı asitlerin etkisi değerlendirilmiştir. Bu kapsamda, ekstraksiyon işlemi $\% 5$ oranında 4 farklı asit (asetik asit, sitrik asit, hidroklorik asit ve laktik asit) kullanılarak tavuk ayağı/çözelti oranı 1:8 (w/v) olacak şekilde farklı sürelerde (12, 24, 36 ve 48 saat) gerçekleştirilmiştir. Çalışma sonucunda, kolajen verimi (\%), kolajen (\%), saf kolajen ( $\mathrm{g}$ $/ 100 \mathrm{~g})$ ve kolajen kayb1 (\%) miktarlar1 kıyaslandığında optimum koşul 36 saat laktik asit uygulamas1 olarak belirlenmiştir. Laktik asit ve asetik asit, kolajen ekstraksiyonu için etkin çözücülerdir. Gómez-Guillén ve Montero (2001), güçlü bir asitin (yüksek $\mathrm{k}_{\mathrm{a}}$ ve düşük $\mathrm{pH}$ değeri) kolajen ekstraksiyon hızını arttırdığını belirtmiştir. Ancak, pH değeri $(<2.0)$ olan asitlerin, ekstraksiyon sirasinda kolajen denatürasyonu ve sindirimine yol açtı̆ı belirtilmiştir (Cheng vd., 2009). Bununla beraber, kuvvetli asitlerin $(\mathrm{pH}<2.0)$ yarattığı düşük $\mathrm{pH}$ ortamının, kolajen ekstraksiyon verimini azalttığını bildiren çalışmalarda literatürde mevcuttur (Liu vd., 2001; Cheng vd., 2009; Lin vd., 2013; Liu ve Huang., 2016).

Asit ile hidroliz yönteminde konsantrasyon, $\mathrm{pH}$ değeri, sıcaklık ve işlem süresi gibi değişkenler ekstraksiyon verimini etkiler. Bununla birlikte, asit ve enzimle hidroliz işlemleri beraber uygulandığında daha yüksek verimlere ulaşıldığı bilinmektedir (Chuaychan vd., 2015; Mahboob, 2015; Ali vd., 2017; Zhang ve Duan, 2017).

\section{Enzimatik Hidroliz}

Enzimatik hidroliz, kompleks moleküllerin monomerlerine ayrıştırlmasının enzimlerin eklenmesiyle gerçekleştirildiği bir işlemdir. 
Proteinlerin enzimatik hidrolizi, proteinlerin fiziksel, kimyasal ve fonksiyonel özelliklerini geliştirmek için önemli bir biyoproses olarak görülmektedir (Sarbon vd., 2018). Proteazlar, proteinlerdeki peptit bağlarını hidrolize ederler ve bu amaçla gida endüstrisinde de yaygin olarak kullanilırlar (Temiz, 2014). Pepsin, papain, ve tripsin kolajen ekstraksiyonu için yaygın olarak kullanılan proteaz enzimleridir (Jung vd., 2014; Yasothai ve Giriprasad, 2015; Liu vd., 2016; Yu vd., 2018). Genellikle telopeptitleri parçalayarak kolajen ekstraksiyonunu kolaylaştıran enzimler bununla birlikte, kolajenin üçlü sarmal yapısını da korur (Chuaychan vd. 2015; Gao vd., 2017). Ali vd. (2018) ve Riaz vd. (2018), Fourier dönüşümü kızılötesi (FTIR) sonuçlarına dayanarak elde ettikleri bulgularla, pepsinin kolajenin üçlü sarmal yapısını koruduğunu göstermişlerdir. Enzimatik hidroliz, kolajen ekstraksiyonu için kullanılan ideal yöntemlerden biri olarak görülür. Çizelge 3'de kolajenin enzimatik hidroliz yöntemiyle ekstraksiyonuna dair çalışmalar verilmiştir.

Çizelge 3. Kolajenin enzimatik hidroliziyle ilgili bazı çalışmalar

\begin{tabular}{|c|c|c|c|}
\hline Materyal & Yöntem & Sonuç & Referans \\
\hline $\begin{array}{l}\text { Kalamar } \\
\text { Derisi }\end{array}$ & $\begin{array}{l}0.5 \mathrm{~mol} / \mathrm{L} \text { asetik asitte, } \\
\text { deri/çözelti oranı } 1: 250(\mathrm{w} / \mathrm{v}) \\
\text { olacak şekilde ve } \% 0.1 \mathrm{pepsin} \\
(\mathrm{w} / \mathrm{w}) \text { kullanılarak } 4{ }^{\circ} \mathrm{C} \text { 'de } 72 \\
\text { saat boyunca karışıtırma işlemi }\end{array}$ & $\begin{array}{l}\text { Kolajen verimi } \% 75.3 \text { (kuru } \\
\text { ağırlı bazında) } \\
\text { belirlenmiştir. ASC verimine } \\
(\% 6.27) \text { kıyasla, kolajen } \\
\text { veriminin belirgin şekilde arttığ1 } \\
\text { gözlenmiştir }\end{array}$ & $\begin{array}{l}\text { Kittiphattanabawon } \\
\text { vd. (2015) }\end{array}$ \\
\hline
\end{tabular}

Tavuk Papain ve pepsin enzimlerinin ayağ1 ekstraksiyon verimine etkisini incelemek amaciyla, \%0.1 (w/v) enzim içeren $0.5 \mathrm{~mol} / \mathrm{L}$ asetik asitte $4{ }^{\circ} \mathrm{C}$ 'de 24 saat boyunca karıştırma işlemi
Papain ve pepsinle ekstrakte edilen kolajen verimleri sirasiyla $\% 18.16$ ve $\% 22.94$ (kuru ağırlik bazında) olarak belirlenmiştir

\begin{tabular}{|c|c|}
\hline $\begin{array}{l}1: 10 \text { (w/v) oranında } 0.5 \mathrm{~mol} / \mathrm{L} \\
\text { organik asit (laktik asit, asetik } \\
\text { asit, sitrik asit) ve } \% 0.1 \text { (w/v) } \\
\text { pepsin kullanılarak } 4^{\circ} \mathrm{C}^{\prime} \mathrm{de} 24 \\
\text { saat karıstırma işlemi }\end{array}$ & 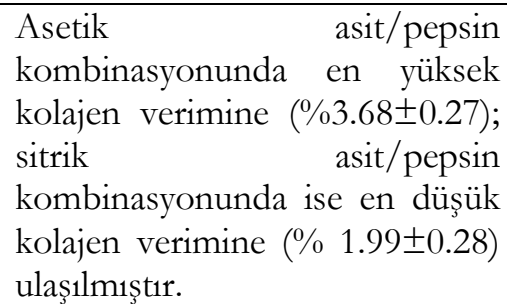 \\
\hline
\end{tabular}

\begin{tabular}{ll}
\hline Koyun & ASC ve pepsinde çözünür \\
kemikleri & kolajen (PSC) özelliklerini \\
& kıyaslama amaciyla, ASC \\
& ekstraksiyonu için, $1: 10$ (w/v) \\
& oranında 0.5 mol/L asetik \\
& asitte, PSC ekstraksiyonu için \\
& pepsin içeren $0.5 \mathrm{~mol} / \mathrm{L}$ asetik \\
& asitte $4^{\circ} \mathrm{C}^{\prime}$ de 3 gün boyunca \\
& karıştırma işlemi
\end{tabular}

Denatürasyon sicaklıklar1 $\left(\mathrm{T}_{\mathrm{d}}\right)$ Gao vd. (2017)

Tavuk karşılaştırıldığında, PSC'nin daha düşük denatürasyon sicaklığına sahip olduğu gözlenmiştir. Amino asit içeriklerinde anlamlı bir fark gözlenmezken, kolajenin önemli bir bileşeni olan hidroksiprolin miktarının PSC'de biraz daha fazla olduğu görülmüştür. 
Enzimatik hidroliz yöntemi diğer yöntemlere göre daha maliyetli olmasına rağmen; yüksek kolajen verimi ve saflığ1 sunar. Bununla beraber, proses kontrolünü kolaylaştırır ve son ürünün özelliklerini iyileştirerek ürün kalitesini arttırır (Iltchenco vd., 2017).

\section{Kolajen Ekstraksiyonunda Ultrason Kullanımı}

Ultrason sözlük anlamı itibariyle, $20 \mathrm{kHz}$ 'in üzerinde bir frekansta herhangi bir sese karşıllk gelir. Düşük ve yüksek şiddetli ultrason olarak sınıflandırılır. Düşük şiddetli ultrason, bir maddenin yapısı, bileşimi, fiziksel durumu gibi fizikokimyasal özelliklerin belirlenmesi için kullanılırken; yüksek şiddetli ultrason, hücre yıkımı, emülsifikasyon, enzimatik inaktivasyon ve kimyasal reaksiyonları desteklemek için kullanılır (Song vd., 2018). Ultrason, siv1 sistemlerde kavitasyon olarak adlandırılan bir etki yaratır. Bu olay sıv1 içinde kabarcık oluşumu, büyümesi ve sönmesiyle ilgilidir (Tavman vd., 2009). Ultrason frekansı arttıkça, sıv1 içinde kavitasyonun yoğunluğu ve üretimi azalır (Chemat vd., 2017).

Ultrasonikasyon, işlem süresini kısaltmak, ürün kalitesini artırmak ve gida ürünlerinin güvenliğini korumak için tasarlanan ve hızla gelişen tekniklerden biri olarak görülmektedir. Son yıllarda kurutma, karıştırma, homojenizasyon ve ekstraksiyon işlemlerindeki kütle transferini hızlandırmak amacıyla yüksek şiddetli ultrasonun kullanıldığı çalışmalar artış göstermiştir (Majid vd., 2015). Ultrasonikasyon işlemi, protein konjugatlarının üretilmesinde ve proteinlerin enzimatik hidrolizinin iyileştirilmesinde etkili bir yöntem olarak görülmektedir (Chen vd., 2011). Kolajen ekstraksiyonunda ultrason kullanımıyla ilgili çalışmalar son yıllarda artış göstermeye başlamıştır. Ali vd. (2017), ultrasonun sazan balığ1 (Probarbus Jullieni) derisinden asitte ve pepsinde çözünür kolajen ekstraksiyonu üzerine etkilerini incelemişlerdir. Ultrasonuygulamasiyla beraber $(20 \mathrm{kHz})$ kolajen veriminin önemli ölçüde arttı̆̆1, işlem süresinin ise kısaldığı görülmüştür. Dairesel dikroizm (CD) ve FTIR sonuçları, ultrason uygulamasıyla elde edilen kolajenlerin üçlü sarmal yapıya sahip olduğunu göstermiştir. Kolajenlerin elektroforez modelleri incelendiğinde, ultrasonun protein yap1s1 ve kolajenin ana bileşenleri olan $\alpha_{1}$, $\alpha_{2}$ ve $\beta$ zincirlerini değiştirmediği görülmüştür. Kim vd. (2013) japon levreği (Lateolabrax japonicus) derisinden kolajen ekstraksiyonu için farklı asetik asit konsantrasyonlarında $(0.01,0.05,0.1 \mathrm{~mol} / \mathrm{L})$ $0-24$ saat aralı̆̆ında ultrason $(20 \mathrm{kHz}$, darbeli mod 20/20 saniye) destekli ekstraksiyon gerçekleştirmişlerdir. Kontrol örneği ise aynı koşullar altında $0.5 \mathrm{~mol} / \mathrm{L}$ asetik asitle ekstrakte edilmiştir. Sonuçlar, ultrason uygulamasının düşük asit konsantrasyonu (0.01 $\mathrm{M})$ kullanıldığında bile, $0.5 \mathrm{~mol} / \mathrm{L}$ asetik asitli geleneksel ekstraksiyon yöntemine göre daha verimli olduğunu göstermiştir. Li vd. (2009) sığır tendonundan pepsinde çözünür kolajen eldesi için ultrason destekli ekstraksiyon $(40 \mathrm{kHz}, 120 \mathrm{~W}$, darbeli mod 30/30 dakika) gerçekleştirmişlerdir. Pepsin uygulamasinda, örnekler $0.5 \mathrm{~mol} / \mathrm{L}$ asetik asit çözeltisi içinde pepsin ile 2 gün boyunca ekstrakte edilmiştir. Ultrason+pepsin uygulamasinda ise ekstra ultrason basamağ haricinde, prosedür pepsin uygulamasiyla tamamen aynıdır. Sonuçlar, ultrason uygulamasının kolajen verimini \%124'e kadar arttırdığını ve işlem süresini önemli ölçüde azalttığını göstermiştir. Sonuçlar, ultrason uygulamasinın enzim aktivitesini ve kolajen substratının çözünmesini arttırarak kolajen fibrillerini açtı̆̆ı, dolayısıyla enzimatik hidrolizi kolaylaştırdığını göstermiştir.

Ultrason teknolojisi, sürdürülebilir 'yeşil' kimyası hedefine ulaşmada önemli bir rol oynar (Chemat vd., 2017). Ultrasonun diğer yöntemlere göre güvenli, ucuz, tekrarlanabilir ve çevre dostu olması gibi pek çok avantajı vardır (Zou vd., 2017). Kolajen ekstraksiyonunda ultrason kullanımı kullanılan asit miktarını ve ekstraksiyon süresini önemli ölçüde azaltmakla beraber, verimi de büyük ölçüde arttırmaktadır (Song vd., 2018). Ancak ultrasonun enzim aktivitesi üzerindeki etkisine dair çalışmalar hala çok sınırlıdır. Bununla birlikte, uzun süreli ultrason uygulaması, ortamda kavitasyona yol açarak basıncın ve sıcaklığın artışına neden olabilir (Schmidt vd., 2016).

\section{SONUÇ}

Literatürdeki çalışmalar incelendiğinde, kolajen ekstraksiyonu için balık yan ürünlerine olan ilginin 
arttığ1 görülmüştür. Yan ürünlerden, katma değeri yüksek kolajen eldesi temiz ve sürdürülebilir üretim açısından önem taşımaktadır. Kolajen ekstraksiyonu için yaygin olarak kullanılan yöntemler; tuzla çöktürme, asitle hidroliz ve enzimatik hidrolizdir. Tuzla çöktürme yönteminde, daha düşük kolajen verimi elde edildiğinden dolayı kullanımı sinırlıdır. Literatürdeki çalışmalar incelendiğinde, asitle hidroliz yönteminin yaygın olarak kullanıldığ1 görülmüştür. Kullanılan asidin türü ve konsantrasyonu kolajen ekstraksiyonu için önemlidir. Asitle hidroliz yönteminin enzimle beraber uygulandığında, daha yüksek verimlere ulaşıldığı bilinmektedir. Kolajen ekstraksiyonu için enzim kullanımı ideal yöntemlerden biridir. Enzimatik hidroliz yönteminin, düşük enerji tüketimi, yüksek kolajen verimi ve saflığ1 sunması, reaksiyon koşullarının hafif olması vb. avantajlara sahip olmasından dolay1 kullanımı tercih edilmektedir. Ultrason kullanımı kolajen yapisına zarar vermeden verimi arttırır, ekstraksiyon süresini ise kısaltır. Yapılan çalışmalar, ultrasonunun ekstraksiyon etkinliğini arttırmak için etkili bir araç olduğunu kantllar niteliktedir. Ancak, ultrasonun enzim aktivitesi ve kolajen yapısı üzerine etkilerinin daha iyi değerlendirilmesi için çalışmalar arttırılmalıdır.

\section{KAYNAKLAR}

Ali, A. M. M., Benjakul, S., Kishimura, H. (2017). Molecular characteristics of acid and pepsin soluble collagens from the scales of golden carp (Probarbus jullieni). Emir J Food Agric, 29(6): 450457.

Ali, A. M. M., Kishimura, H., Benjakul, S. (2018). Extraction efficiency and characteristics of acid and pepsin soluble collagens from the skin of golden carp (Probarbus Jullieni) as affected by ultrasonication. Process Biochem, 66: 237-244.

Arumugam, G. K. S., Sharma, D., Balakrishnan, R. M., Ettiyappan, J. B. P. (2018). Extraction, optimization and characterization of collagen from sole fish skin. Sustainable Chem Pharm, 9: 1926.

Avila Rodríguez, M. I., Rodríguez Barroso, L. G., Sánchez, M. L. (2018). Collagen: A review on its sources and potential cosmetic applications. $J$ Cosmet Dermatol, 17: 20-26.

Balasubramanian, P., Prabhakaran, M. P., Sireesha, M., Ramakrishna, S. (2012). Collagen in human tissues: structure, function, and biomedical implications from a tissue engineering perspective. In: Polymer Composites-Polyolefin Fractionation-Polymeric Peptidomimetics-Collagens, Pasch, H.(chief ed.), Springer, Berlin, Heidelberg, pp. 173-206.

Bhagwat, P. K., Dandge, P. B. (2016). Isolation, characterization and valorizable applications of fish scale collagen in food and agriculture industries. Biocatal Agric Biotechnol, 7, 234-240.

Bhagwat, P. K., Dandge, P. B. (2018). Collagen and collagenolytic proteases: A review. Biocatal Agric Biotechnol, 15: 43-55.

Bu, Y., Elango, J., Zhang, J., Bao, B., Guo, R., Palaniyandi, K., Robinson, J. S., Geevaretnam, J., Regenstein, J. M., Wu, W. (2017). Immunological effects of collagen and collagen peptide from blue shark cartilage on 6T-CEM cells. Process Biochem, 57: 219-227.

Chemat, F., Rombaut, N., Sicaire, A. G., Meullemiestre, A., Fabiano-Tixier, A. S., AbertVian, M. (2017). Ultrasound assisted extraction of food and natural products. Mechanisms, techniques, combinations, protocols and applications. A review. Ultrason Sonochem, 34: 540560.

Chen, J., Li, L., Yi, R., Xu, N., Gao, R., Hong, B. (2016). Extraction and characterization of acidsoluble collagen from scales and skin of tilapia (Oreochromis niloticus). LWT-Food Sci Technol, 66: 453-459.

Chen, L., Chen, J., Ren, J., Zhao, M. (2011). Effects of ultrasound pretreatment on the enzymatic hydrolysis of soy protein isolates and on the emulsifying properties of hydrolysates. $J$ Agric Food Chem, 59(6): 2600-2609.

Cheng, F.Y., Hsu, F.W., Chang, H.S., Lin, L.C., Sakata, R. (2009). Effect of different acids on the extraction of pepsin-solubilised collagen containing melanin from silky fowl feet. Food Chem, 113(2): 563-567. 
Chuaychan, S., Benjakul, S., Kishimura, H. (2015). Characteristics of acid-and pepsin-soluble collagens from scale of seabass (Lates calcarifer). LWT-Food Sci Technol, 63(1): 71-76.

De Moraes, M. C., Cunha, R. L. (2013). Gelation property and water holding capacity of heattreated collagen at different temperature and $\mathrm{pH}$ values. Food Res Int, 50(1): 213-223.

Dhakal, D., Koomsap, P., Lamichhane, A., Sadiq, M. B., Anal, A. K. (2018). Optimization of collagen extraction from chicken feet by papain hydrolysis and synthesis of chicken feet collagen based biopolymeric fibres. Food Biosci, 23: 23-30.

Dong, X. B., Li, X., Zhang, C. H., Wang, J. Z., Tang, C. H., Sun, H. M., Jia, W., Li, Y., Chen, L. L. (2014). Development of a novel method for hot-pressure extraction of protein from chicken bone and the effect of enzymatic hydrolysis on the extracts. Food Chem 157: 339-346.

Duan, L., Li, J., Li, C., Li, G. (2013). Effects of $\mathrm{NaCl}$ on the rheological behavior of collagen solution. Korea-Aust Rheol J, 25(3): 137-144.

Dun, R., Jackson, H. T., Smith, Y. (2008). Methods for processing and utilization of low cost fishes: a critical appraisal. J Food $S_{c i}$ Technol, 32: 1-12.

Duong-Ly, K. C., Gabelli, S. B. (2014). Salting out of proteins using ammonium sulfate precipitation. Methods Ensymol, 541: 85-94.

Ehrlich, H., Wysokowski, M., ZółtowskaAksamitowska, S., Petrenko, I., Jesionowski, T. (2018). Collagens of Poriferan Origin. Mar Drugs, 16(3): 1-21.

Ferraro, V., Martinie, B.G., Sayd, T., Chambon, C., Anton, M., Lhoutellier, V.S. (2017). Collagen type I from bovine bone. Effect of animal age, bone anatomy and drying methodology on extraction yield, self-assembly, thermal behaviour and electrokinetic potential. Int J Biol Macromol, 97: 55-66.

Gao, L. L., Wang, Z. Y., Li, Z., Zhang, C. X., Zhang, D. Q. (2017). The characterization of acid and pepsin soluble collagen from ovine bones (Ujumuqin sheep). J Integr Agr,17(3): 704-711.
Gelse, K., Pöschl, E., Aigner, T. (2003). Collagens - structure, function, and biosynthesis. Adv Drug Delivery Rev, 55: 1531-1546.

Gómez-Guillén, M. C., Giménez, B., LópezCaballero, M. E., Montero, M. P. (2011). Functional and bioactive properties of collagen and gelatin from alternative sources: A review. Food Hydrocoll, 25(8): 1813-1827.

Gómez-Guillén, M. C., Montero, P. (2001). Extraction of gelatin from megrim (Lepidorbombus boscii) skins with several organic acids. J Food Sci, 66(2): 213-216.

Hashim, P., Ridzwan, M. M., Bakar, J. (2014). Isolation and characterization of collagen from chicken feet. Int J Bioeng Life Sci, 8(3): 250-254.

Huang, C. Y., Kuo, J. M., Wu, S. J., Tsai, H. T. (2016). Isolation and characterization of fish scale collagen from tilapia (Oreochromissp.) by a novel extrusion-hydro-extraction process. Food chem, 190: 997-1006.

Iltchenco, S., Kempka, A. P., Prestes, R. C. (2017). Profiles of enzymatic hydrolysis of different collagens and derivatives over time. R Bras Tecnol Agroindustr, 11(1): 2165-2185.

Jeevithan, E., Jingyi, Z., Wang, N., He, L., Bao, B., Wu, W. (2015). Physico-chemical, antioxidant and intestinal absorption properties of whale shark type-II collagen based on its solubility with acid and pepsin. Process Biochem, 50(3): 463-472.

Jeevithan, E., Wu, W., Nanping, W., Lan, H., Bao, B. (2014). Isolation, purification and characterization of pepsin soluble collagen isolated from silvertip shark (Carcharbinus albimarginatus) skeletal and head bone. Process Biochem, 49(10): 1767-1777.

Jung, K. H., Choi, Y. C., Chun, J. Y., Min, S. G., Hong, G. P. (2014). Effects of concentration and reaction time of trypsin, pepsin, and chymotrypsin on the hydrolysis efficiency of porcine placenta. Korean J Food Sci Anim Resour, 34(2): 151-157.

Kadler, K. E., Baldock, C., Bella, J., BootHandford, R. P. (2007). Collagens at a glance. J Cell Sci, 120(12): 1955-1958. 
Kaewdang, O., Benjakul, S., Kaewmanee, T., Kishimura, H. (2014). Characteristics of collagens from the swim bladders of yellowfin tuna (Thunnus albacares). Food Chem, 155: 264-270.

Karsdal, M. A., Mortensen, J. H. (2016). Type VII collagen. In: Biochemistry of collagens, laminins and elastin: structure, function and biomarkers, Karsdal, M. A. (chief ed.), Academic Press, Denmark, pp. 5760.

Kim, H. K., Kim, Y. H., Park, H. J., Lee, N. H. (2013). Application of ultrasonic treatment to extraction of collagen from the skins of sea bass Lateolabrax japonicus. Fish sci, 79(5): 849-856.

Kittiphattanabawon, P., Nalinanon, S., Benjakul, S., Kishimura, H. (2015). Characteristics of pepsin-solubilised collagen from the skin of splendid squid (Loligo formosana). J Chem, 2015: 18.

Krishnamoorthi, J., Ramasamy, P., Shanmugam, V., Shanmugam, A. (2017). Isolation and partial characterization of collagen from outer skin of Sepia pharaonis (Ehrenberg, 1831) from Puducherry coast. Biochem biophys rep, 10: 39-45.

Lafarga, T., Hayes, M. (2014). Bioactive peptides from meat muscle and by-products: generation, functionality and application as functional ingredients. Meat Sci, 98(2): 227-239.

Li, D., Mu, C., Cai, S., Lin, W. (2009). Ultrasonic irradiation in the enzymatic extraction of collagen. Ultrason sonochem, 16(5): 605-609.

Li, J., Wang, M., Qiao, Y., Tian, Y., Liu, J., Qin, S., Wu, W. (2018). Extraction and characterization of type I collagen from skin of tilapia (Oreochromis niloticus) and its potential application in biomedical scaffold material for tissue engineering. Process Biochem, 74: 156-163.

Li, P., Wu, G. (2018). Roles of dietary glycine, proline, and hydroxyproline in collagen synthesis and animal growth. Amino Acids, 50(1): 29-38.

Liang, Q., Wang, L., Sun, W., Wang, Z., Xu, J., $\mathrm{Ma}, \mathrm{H}$. (2014). Isolation and characterization of collagen from the cartilage of Amur sturgeon (Acipenser scbrenckii). Process Biochem, 49(2): 318323.
Lin, C. W., Loughran, M., Tsai, T. Y., Tsai, S. W. (2013). Evaluation of convenient extraction of chicken skin collagen using organic acid and pepsin combination. J. Chin. Soc. Anim. Sic, 42(1): 27-38.

Liu, D. C., Lin, Y. K., Chen, M. T. (2001). Optimum Condition of Extracting Collagen from Chicken Feet and its Characteristics. AsianAustralas J Anim Sci, 14(11): 1638-1644.

Liu, D., Wei, G., Li, T., Hu, J., Lu, N., Regenstein, J. M., Zhou, P. (2015a). Effects of alkaline pretreatments and acid extraction conditions on the acid-soluble collagen from grass carp (Ctenopharyngodon idella) skin. Food Chem, 172: 836843.

Liu, D., Zhang, X., Li, T., Yang, H., Zhang, H., Regenstein, J. M., Zhou, P. (2015b). Extraction and characterization of acid-and pepsin-soluble collagens from the scales, skins and swimbladders of grass carp (Ctenopharyngodon idella). Food Biosci, 9: 68-74.

Liu, H., Huang, K. (2016). Structural Characteristics of Extracted Collagen from Tilapia (Oreochromis mossambicus) Bone: Effects of Ethylenediaminetetraacetic Acid Solution and Hydrochloric Acid Treatment. Int J Food Prop, 19(1): 63-75.

Liu, Y., Andarawis-Puri, N., Eppell, S. J. (2016). Method to extract minimally damaged collagen fibrils from tendon. J Biol Methods, 3(4): e54.

Lodish, H., Berk, A., Zipursky, S.L., Matsudaira, P., Baltimore, D., Darnell, J. (2000). Molecular Cell Biology. Section 22.3 : Collagen: The Fibrous Proteins of the Matrix, Edited by W. H. Freeman, New York.

Mahboob, S. (2015). Isolation and characterization of collagen from fish waste material- skin, scales and fins of Catla catla and Cirrbinus mrigala. J Food Sci Technol, 52(7): 4296-4305.

Majid, I., Nayik, G. A., Nanda, V. (2015). Ultrasonication and food technology: A review. Cogent Food Agric, 1(1): 1071022.

Manjula, U. D. P., Jayamanne, S. C., Thushari, G. G. N. (2015). Effect of pretreatment on physical 
properties of yellow fin tuna (Thunnus albacares) fish glue. Int J Fish Aquat Stud, 2(4S): 14-21.

Mohammadi, R., Mohammadifar, M. A., Mortazavian, A. M., Rouhi, M., Ghasemi, J. B., Delshadian, Z. (2016). Extraction optimization of pepsin-soluble collagen from eggshell membrane by response surface methodology (RSM). Food chem, 190: 186-193.

Ninan, G., Joseph, J., Aliyamveettil, Z. A. (2014). A comparative study on the physical, chemical and functional properties of carp skin and mammalian gelatins. J Food Sci Tecbnol, 51(9): 2085-2091.

Ran, X. G., Wang, L. Y. (2014). Use of ultrasonic and pepsin treatment in tandem for collagen extraction from meat industry by-products. J $S_{c i}$ Food Agric, 94(3): 585-590.

Riaz, T., Zeeshan, R., Zarif, F., Ilyas, K., Muhammad, N., Safi, S. Z., Rahim, A., Rizvi, S. A. A., Rehman, I. U. (2018). FTIR analysis of natural and synthetic collagen. Appl Spectrosc Rev, 53(9): 703-746.

Ricard-Blum, S. (2011). The collagen family. Cold Spring Harb Perspect Biol, 3: 1-19.

Sarbon, N. M., Badii, F., Howell, N. K. (2018). Purification and characterization of antioxidative peptides derived from chicken skin gelatin hydrolysate. Food Hydrocoll, 85: 311-320.

Schmidt, M. M., Dornelles, R. C. P., Mello, R. O., Kubota, E. H., Mazutti, M. A., Kempka, A. P., Demiate, I. M. (2016). Collagen extraction process. Int Food Res J, 23(3): 913-922.

See, S. F., Ghassem, M., Mamot, S., Babji, A. S. (2015). Effect of different pretreatments on functional properties of African catfish (Clarias gariepinus) skin gelatin. J Food Sci Technol, 52(2): 753-762.

Sibilla, S., Godfrey, M., Brewer, S., Budh-Raja, A., Genovese, L. (2015). An Overview of the Beneficial Effects of Hydrolysed Collagen as a Nutraceutical on Skin Properties: Scientific Background and Clinical Studies. Open Nutracenticals J, 8: 29-42.
Simões, G. S., Silveira, E. T. F., de Oliveira, S. R., Poleze, E., Allison, J. R., Ida, E. I., Shimokomaki, M. (2014). Optimum conditions for extracting collagen from the tunica albuginea of immunologically castrated pig testes and the functional properties of the isolated collagen. Meat Sci, 96(4): 1460-1468.

Sionkowska, A., Kozłowska, J., Skorupska, M., Michalska, M. (2015). Isolation and characterization of collagen from the skin of Brama australis. Int J Biol Macromol, 80: 605-609.

Song, H., Li, B. (2017). Beneficial Effects of Collagen Hydrolysate: A Review on Recent Developments. Biomed J Sci \& Tech Res, 1(2): 1-4.

Song, K. M., Jung, S. K., Kim, Y. H., Kim, Y. E., Lee, N. H. (2018). Development of industrial ultrasound system for mass production of collagen and biochemical characteristics of extracted collagen. Food Bioprod Process, 110: 96103.

Sun, L., Hou, H., Li, B., Zhang, Y. (2017). Characterization of acid-and pepsin-soluble collagen extracted from the skin of Nile tilapia (Oreochromis niloticus). Int J Biol Macromol, 99: 8-14.

Tavman, Ş., Kumcuoğlu, S., Akkaya, Z. (2009). Bitkisel ürünlerin atıklarından antioksidan maddelerin ultrason destekli ekstraksiyonu. GID A, 34(3): 175-182.

Temiz, A. (2014). Enzimler. Grda Kimyası, Saldamlı, İ. (baş ed.), Hacettepe Üniversitesi Yayınları, Ankara, Türkiye, s. 392.

Tsutaya, T., Takahashi, T., Schulting, R. J., Sato, T., Yoneda, M., Kato, H., Weber, A. W. (2018). Effects of lipid extraction and different collagen extraction methods on archaeological fish bones and its implications for fish bone diagenesis. $J$ Archaeol Sci Rep, 20: 626-633.

Oechsle, A. M., Akgün, D., Krause, F., Maier, C., Gibis, M., Kohlus, R., Weiss, J. (2016). Microstructure and physical-chemical properties of chicken collagen. Food Struct, 7: 29-37.

Wang, L., Yang, B., Du, X., Yang, Y., Liu, J. (2008). Optimization of conditions for extraction of acid-soluble collagen from grass carp (Ctenopharyngodon idella) by response surface 
methodology. Innovative Food Sci Emerg Technol, 9(4): 604-607.

Włodarczyk, M. G., Kubisz, L., Włodarczyk, D. (2017). Amino acid composition in determination of collagen origin and assessment of physical factors effects. Int J Biol Macromol, 104: 987-991.

Xu, S., Yang, H., Shen, L., Li, G. (2017). Purity and yield of collagen extracted from southern catfish (Silurus meridionalis Chen) skin through improved pretreatment methods. Int $J$ Food Prop, 20(sup1): S141-S153.

Yang, H., Shu, Z. (2014). The extraction of collagen protein from pigskin. J Chem Pharm Res, 6(2): 683-687.

Yasothai, R., Giriprasad, R. (2015). Extraction of protein by enzymatic hydrolysis. Int J Environ $S_{c i}$ Technol, 4(1): 190-192.

Yu, F., Zong, C., Jin, S., Zheng, J., Chen, N., Huang, J., Chen, Y., Huang, F., Yang, Z., Tang, Y., Ding, G. (2018). Optimization of Extraction Conditions and Characterization of Pepsin-
Solubilised Collagen from Skin of Giant Croaker (Nibea japonica). Mar Drugs, 16(1): 29.

Zhang, J., Duan, R. (2017). Characterisation of acid-soluble and pepsin-solubilised collagen from frog (Rana nigromaculata) skin. Int J Biol Macromol, 101: 638-642.

Zhou, C., Li, Y., Yu, X., Yang, H., Ma, H., Yagoub, A. E. A., Cheng, Y., Hu, J., Otu, P. N. Y. (2016). Extraction and characterization of chicken feet soluble collagen. LWT-Food Sci Technol, 74: 145-153.

Zhou, P., Regenstein, J. M. (2005). Effects of alkaline and acid pretreatments on Alaska pollock skin gelatin extraction. J Food Sci,70(6): c392c396.

Zou, Y., Xu, P., Li, P., Cai, P., Zhang, M., Sun, Z., Sun, C., Xu, W., Wang, D. (2017). Effect of ultrasound pre-treatment on the characterization and properties of collagen extracted from softshelled turtle (Pelodiscus sinensis). LWT-Food Sci Technol, 82: 72-81. 